\title{
Reflection on Action: The Use of Reflective Journal Plus Video Recording
}

\author{
Yuli Tiarina and Yenni Rozimela \\ English Department \\ Universitas Negeri Padang \\ Padang, Indonesia \\ yulitiarina@yahoo.co.id
}

\begin{abstract}
This article discusses a partial result of a study conducted to look at the implementation of reflective teaching to improve student-teachers' pedagogic competence in Micro Teaching Class and Teaching Practicum subject. The focus of this report is to describe the use of reflective journals plus video recording as tools used by the prospective teachers for reflective teaching. Thus, the emphasis will be on the extent to which the combination of these tools helps the student-teachers improve their teaching skill. This action research employs qualitative approach. The data were collected through teaching performance assessment, observation, and interview. This research was carried out in Micro Teaching class consisting of 19 students. There were three procedures implemented in this research. First, the student-teachers were asked to perform their teaching. The teaching performance of each-student teacher was videorecorded by the researchers. The student-teachers were asked to reflect upon their teaching and watch their own teaching performance and write the results of the reflection in a journal. Second, the student-teachers performed their second teaching. Again, their teaching performance was recorded. Before receiving comments from the lecturer and their peers, they were asked to articulate what they thought about their performance. Similar to the first cycle, the student-teachers were asked to reflect upon their teaching practice, watch the recording, and write the results of reflection in their journals. The same procedure was applied at the third cycle. The findings of this study regarding the use of journal and video indicate that these tools are effective in helping students improve their teaching skill. In fact, quantitatively, the students' teaching skill improved as indicated by the comparison of the scores they gained in the three teaching cycles. Based on the qualitative analysis, it was found that the student-teachers got benefits from their reflective journal plus video recording. Their writing in the journals revealed that most of them were aware of their weaknesses, and thus made improvement in the corresponding points. Furthermore, in the interview they said that watching video gave them a vivid idea how their teaching was like.
\end{abstract}

Keywords- pedagogic competence; reflection; reflective journal; video recording

\section{INTRODUCTION}

Microteaching is an essential component in language teaching program. Toman \& Cimer \& Cimer [1] have investigated 32 students who believed that microteaching gives benefits to their teaching skill. At English Department of Universitas Negeri Padang, Microteaching has become one of compulsory subjects.[2] It promotes the students with pedagogical skills that the teacher must have. Microteaching is a technique aiming to prepare prospective teachers to the real classroom setting. Microteaching can be defined as a teaching technique particularly used in teachers' pre-service education to train them systematically and to experiment main teacher behaviors [3].

Generally, the technique used by the lecturers in teaching microteaching at English Department of UNP tends to be monotonous. The students take turn teaching their friends based on the lesson plan they made. Then, the lecturer gives comment on his/her teaching performance. The students wait for, listen to and accept the comments from the lecturer. They become passive listeners.

What they need to get after acting as a teacher is not only comments or inputs from their lecturer, but also their own reflection on their teaching skills. They need to evaluate themselves whether (1) they reached the purpose, (2) they used appropriate technique, media, and material, (3) they involved the students (made the students active), and (4) they used English accurately and fluently. The students need to reflect their own teaching performance. After performing their teaching, they must become active speakers. They must think critically upon what they did during teaching.[4]As pragmatists emphasize that teaching should focus on critical thinking. This critical thinking will lead the students to have reflective thinking. Wilson and Jane [1] in Toman claim reflective thinking as a process of self-evaluation. Further, Toman \& Cimer \& Cimer [1] discuss that students who can evaluate themselves can create goals and they can follow how they achieved these goals. In addition, they can evaluate the results they have obtained and generate new ways of solutions after discovering their weaknesses. Finally, if the students find their strengths, they can enhance them. [5] Lieberman and Diane say that teachers need to sustain their professional development by reflecting on teaching through reflection on learning. In other words, teachers need to do reflective teaching. Reflective thinking is needed in reflective teaching. 
Teachers need to do reflective teaching. They need to pay attention to everything in the classroom during their instruction. They think of the objectives and the targets to be achieved, do objective observations, and then diversify the methods with respect to the classroom atmosphere. [6] Reflective teaching requires a lasting self-observation and self-evaluation in order to figure out both own and students' behaviors and responses. Reflective teaching demands teachers to look back at their particular teaching presentation and take some time to evaluate the strengths and the weaknesses of their teaching presentation.

There are some tools or strategies used in reflective teaching. Tice [7] classifies the tools into teacher diary, peer observation, recording lesson and students' feedback. Farrel and Jado [8] use the term journal writing learning journal instead of teacher diary. Toman\& Cimer \& Cimer [1] names it reflective journal. While Karaca [9] calls it reflective diary. In short, written reflection can be called teacher diary, journal writing, learning journal, or teacher diary. To differentiate and show the specific function of the journal, the researcher calls it reflective journals.

Many researchers have conducted the research about reflective thinking, reflective teaching and its tools or strategies. Kong [10] reports the development of video recording for the operationalisation of the reflective process. Fatemipour [11] has investigated which tool is the most effective. He found that teacher diary is the most effective reflective tool. Toman \& Cimer \& Cimer [1] also investigate the pre-service teachers' view about reflective teaching methods, namely microteaching, lesson plan, self-evaluation and reflective journal. Karaca [9] has found that journal is one of reflective teaching tool that improves the first-year preservice science teachers' achievement scores, and the majority of the participants believed that the activities had positive effects on their meta-cognition and learning. In line, [8]Jado found that learning journals is effective on self-regulated learning and reflective thinking among a sample of pre-service teachers. Similarly, [12] Ogbuanya found that reflective inquiry instructional technique is effective on achievement of students in Technical College.

The problem under investigation in this study is that while some experts in reflective teaching investigate the effectiveness of one tool that is journal. They do not find out what recommended by Fatemipour. [11]Fatemipour recommends teachers to apply more than one tool to obtain more reliable data. This article is derived from a research, entitled Applying Reflective Teaching to Improve Students' Pedagogic Competence in Teaching Practice in Micro Teaching Subject. The first step in this research is the students have other students comment on their teaching practice. The second step is the students reflect their own teaching and write it in their journal.It was found that most prospective teachers got comment from their friends about teaching technique, media and material[13].

This article, then, is derived from a research, entitled Applying Reflective Teaching to Improve Students' Pedagogic Competence in Teaching Practice in Micro
Teaching Subject [13]. One of the purposes of the research is to find out the effect of reflective teaching on prospective teachers pedagogic competence. Regarding the aforementioned research problem, the purpose of the present study is to investigate the effectiveness of two reflective teaching tools, namely reflective journal plus video recording, on students' teaching skills. In other words, the researcher wants to determine whether reflective journal plus video recording gives better effect on students' teaching skills.

Richards \& Lockhart [14] define reflective teaching as an activity or process of responding to a past experience. [15] It is "deliberating on experince, and that of mirroring experience. It is a conscious effort to recall, consider, and evaluate a past experience of teaching. The results of the reflection are used as a basis for evaluation and decisionmaking and as a source of planning and action for the next teaching. [6] The teachers can ask "how else can I teach?" and "What and how can I teach now?" [16][7] Reflective teaching is effective for teachers' development since it encourages the teachers to look at ways of managing the classroom and students from differing perspectives, based on data in the field.

Tice [7] reminds the teachers that reflective teaching is a systematic process of collecting, recording, and analyzing teachers' reflective thinking and observations, as well as those of our students, and then going on to. It is not only teachers' talk in teachers' meeting room.

There are five related components in reflection process proposed by Farrel on the basis of the experiences of an EFL development group in Korea [15]. First, teachers should be given different opportunities through different activities such as group discussions, observation, and journal writing. Second, ground rules have to be built to the process and into each activity. For journal writing, for example, a minimum guideline needs to be negotiated to insure a critical reflection. Third, teachers should be provided with distinct types of times which include time for individual, activity, development, and period of reflection. Fourth, teachers should be provided with teachers need to be provided with external input for enriched reflection. Other people's comments drawn from observations, experiments, research, and theories should be useful input for critical reflection. Fifth, teachers should be in a low affective state. A non-threatening environment needs to be created to reduce anxiety.

Teachers can do reflection their teaching skills by collecting their own data about their teaching. There some tools, strategies or approach to collect the data for reflective teaching. [14]Richards \& Lockhart classify them into teaching journals, lesson reports, survey and questionnaires, audio and video recording, observation and action research. Similarly, [7]Tice groups them into teacher diary, peer observation, recording lesson and students' feedback.

[1]Journals are the materials in which students record their own personal reactions, questions, feelings, changing ideas, thoughts, learning processes, and the knowledge related to their learning content. Students do not simply discuss their experiences during the learning process in reflective journals. 
These writings include the explanations, analysis, and reflections which students make about their learning.

[17]Keeping a teaching journal is a data-gathering activity through which teachers can gain awareness and express their attitudes. Teachers who keep journals of their own teaching may differ in their attitudes and awareness from those who do not. In addition, journals are effective for students to actively engage in a course or any learning activity. An important effect of reflective journals is that teachers can get feedback about the curriculum which they implement from the students' reflective writings. Therefore, teachers can design more suitable teaching and learning activities for the students. Teachers can also write about the curriculum which they implement and their teaching behaviors. [1]These pieces of writings can give them opportunities to evaluate the curricula they have implemented, teaching approaches, and themselves.

[18]Bailey mentions some examples of successful stories of keeping journals by teachers. Telatnik, an inexperienced ESL teacher who kept a journal reported that her journal changed her attitude toward getting feedback. She said that she became more objective and honest about other people's analysis of her teaching. She admitted that she had run a teacher-centered teaching. After all, she managed to gleana few techniques to encourage her students to participate. Another story mentioned by Bailey is the experience of Verity, an experienced ESL teacher and teacher educator. She kept a journal of the first she taught at a university in Japan. She said that "the teaching journal became a zone for thinking"that enabled herto externalize and make her thoughts and feelings explicit[18]. Through keeping a journal she reconstructed her existing knowledge in her new teaching context. These two stories indicate that keeping a journal is an effective way to do reflection in teaching.

For many aspects of teaching, it is believed that audio or video recording of lessons can also provide a basis for reflection. While there are many useful insights to be gained from diaries and self-reports, they cannot capture the moment to moment processes of teaching. Many things happen simultaneously in a classroom, and some aspects of a lesson cannot be recalled. It would be of little value for example, to attempt to recall the proportion of Yes-No Questions to WHQuestions a teacher used during a lesson, or to estimate the degree to which teacher time was shared among higher and lower ability students. Many significant classroom events may not have been observed by the teacher; it is better to supplement diaries or self-reports with recordings of actual lessons[19].

It is said that videos taken during lessons in teaching practice are trustworthy data for student teachers to make a post-lesson self-reflection that is grounded in the actual records rather than uncertain recollections. It is found that (student) teachers show significant growth in the levels of reflective thoughts about their teaching work, under a guiding framework for self-reflection, after browsing video recordings of lessons in teaching practice. The use of videos is thus considered to be helpful in enhancing the depth and quality of self-reflection by student teachers. [10]Video recordings of lessons in teaching practice can provide student teachers with specific information for the analysis and evaluation of their classroom teaching performance, from an observer perspective, with an unlimited access.

Since 2006 in Indonesia, particularly, genre-based approach has been used to teach English. Genre-based pedagogy was proposed by Martin in 1979, and has is widely used in language teaching[20]. The approach starts with learning the structures of the target genre through independent writing. [1] The approach promotes understanding, analysis, synthesis, solving problems, and thinking meta-cognitively in order to decode texts efficiently and to become equipped with knowledge about the features of texts for constructing effective written text. [21]As a result, the main goal of the approach is to learn languages through mainstream text types based on language use in a social context or for a particular purpose in a situation.

\section{METHOD}

This action research uses qualitative approach. The data were collected through teaching performance assessment, observation, and interview. This research was carried out in Micro Teaching class consisting of 19 students. The data were collected through observation and interview. The observation checklist contained five main indicators including teaching techniques or strategies, instructional materials, teaching media, classroom language, and classroom management. Interview guide also consisted of five main questions from the five indicators. The students' teaching performance was assessed on the five indicators, too. The results of the observation and interview were analyzed qualitatively.

There were three procedures implemented in this research. First, the student-teachers were asked to perform their teaching. The teaching performance of each-student teacher was video-recorded by the researchers. The student-teachers were asked to reflect upon their teaching and watch their own teaching performance and write the results of the reflection in a journal. Second, the student-teachers performed their second teaching. Again, their teaching performance was recorded. Before receiving comments from the lecturer and their peers, they were asked to articulate what they thought about their performance. Similar to the first cycle, the student-teachers were asked to reflect upon their teaching practice, watch the recording, and write the results of reflection in their journals. The same procedure was applied at the third cycle.

\section{RESULT AND FINDING}

This part explains the results of observation and interview. The result of observation shows that the studentteachers improved their teaching performance in aspects of teaching techniques, teaching materials, and instructional media. However, improvement of the use of classroom language was insignificant. The result of interview supported the result of observation. The student-teachers perceived that using journal plus video helped them in reflection. Detailed description is given below.

\section{Observation Result}


As stated in the previous part, the observation focused on five teaching aspects (teaching techniques, materials, media, classroom management, and classroom language).

The results of the observation indicate that the students showed promising progress of varying degrees in all aspects. The most improvement was evident in the selecting and applying the selected teaching techniques and selecting instructional materials. The improvement of the other aspects can be considered moderate. A comparison between the result of the first cycle and the second cycle of each teaching aspect is described below in order to show the progress.

a. Teaching techniques

At the first cycle it was found that the student-teachers had problems in selecting the teaching techniques and ordering the activities. Almost all student-teachers used similar teaching and learning activities. Teaching interactional texts such as greeting' and 'asking for opinion', they tended to use the following procedures:

- giving a brief review of related background knowledge either through question and answer or through media

- appointing a couple of students to read the models of conversations given

- $\quad$ asking the students to repeat after the teacher

- introducing selected expressions of the interactional text

- $\quad$ asking the students to work in pair to create their own conversations/dialogues

From these activities it can be seen that the studentteachers used quite monotonous activities and skipped some important aspects they had to include in their teaching. They did not discuss the content of the conversation models. They did not give examples of the use of different language expressions in context. For instance, they did not explain and give authentic use of "can you ..., could you ..., I wonder if ....' They did not introduce new vocabulary either. Furthermore, they did not give guided practices or exercises before they asked the students to create their own conversations. As their students were their peers, they were not aware of the fact that the students at schools would not be able to create their conversations without step by step guidance.

The student-teachers were given feedback on their teaching performance. Then, they were required to watch their performance, do some reflection, and write their journals. We read their journals and we found out that all students wrote their comments on the teaching techniques they used. They were not satisfied with their performance and they wrote that they had to make some improvement.

At the second cycle, the improvement was evident. The student-teachers used a wider variation of teaching techniques. Here are examples of activities used by a student-teacher.

- Using a video to activate the students' background knowledge about asking for a direction

Discussing the content of the video

- Introducing prepositions for telling directions with examples aided with a map
- Giving a model of conversation and asking the students to read silently first.

- Asking 2 pairs of students to read the conversation

- Introducing important language expressions and discussing their use in context.

- Showing a map through which the students were required to practice 'asking and giving direction'.

- Asking the students to 'role play' to practice 'asking and giving direction.

- Drawing a conclusion about the lesson of the day

To conclude the results of the second cycle, all studentteachers discussed the content of the conversation models through question and answer technique. All of them (90\%) gave examples of the use of different language expressions although some did not do it well. In addition, all students introduced some new vocabulary. They also managed to give guided exercises before asking the students to create their own conversations.

For teaching monolog texts such as recount, there was also improvement at the second cycle. At the first cycle the student-teachers hardly taught reading strategies, built vocabulary. Most of the student-teachers used the following techniques and activities.

- Activating the students' background knowledge related to the topic and the type of the text through question and answer technique with video or pictures

- Asking certain students to read a text loudly

- Asking a few questions orally to check the students' general comprehension

- Introducing the generic structure of the text

- Asking the students to read the text again silently and answering preplanned written questions

- Checking the answers together

- Giving another text and asking them to answer the written questions after the text

- Collecting the students' answers

- Concluding the lesson

It should be noted that the students did not have difficulties in understanding the texts; they could answer the questions quite easily. Apparently, the texts were intended for high school students, meaning that they were easy for university students who acted as students in the micro teaching class. In effect, there were no questions related to vocabulary and sentence level understanding. In spite of that, the result of the observation indicated that the student-teachers did not teach the students how to read. In fact, there were reading strategies taught and no scaffolding to understand a text given. Moreover, it was thought that the techniques used seemed to be boring for high school students. Because of that, the student-teachers were told to reflect upon their teaching, watched the recording of their teaching, and put themselves as high school students, and wrote what they thought about their teaching performance in their journals.

At the second cycle $50 \%$ of the student-teachers improved the techniques of teaching reading. The rest made insignificant progress. An example of teaching procedures of those who made changes is as follows. 
- Activating the students' background knowledge through question and answer aided with video solar eclipse

- $\quad$ Requiring each student to take a piece of paper and make 3 columns, what s/he has known about solar eclipse, what s/he wants to know about it, and what s/he learned from the text. S/he was asked to fill the first and the second columns. The student-teacher used KWL strategy.

- Asking the students to read the text distributed by the teacher and filling the third column.

- Inviting some students to tell what they wrote in the three columns.

- $\quad$ Requiring the students to read the text again and answer the questions

- Discussing the answers with the students while introducing the strategies to find the main idea of each paragraph of the text.

- Explaining the generic structure by referring to the text

- Highlighting some new vocabulary and asking the students to guess the meaning

- Giving a vocabulary exercise inform of crossword puzzle

\section{- Concluding the lesson}

Those who did not make significant improvement only added vocabulary building exercise and used more variation of question types. Scaffolding the students to understand the text and teaching reading strategies were still not applied well.

For writing skill there were only two of the eight studentteachers teaching writing who showed progress. It was found that teaching writing was quite difficult for the studentteachers. They did not teach the students to write, but only gave instruction to write. The following are the teaching techniques used by the student-teachers at the first cycle.

- $\quad$ Reviewing the generic structure and the language features of the genre to be developed. All of the student-teachers did this through question and answer strategy.

- Asking the students to write in small groups or brainstorming for ideas briefly.

- $\quad$ Asking a student to present his/her writing and asking the other students to give comments

Asking the students to revise and edit their writing

At the second cycle, as mentioned above, two student-teachers made substantial improvement. They showed the students how to write. They exemplified how to generate ideas, clustered the ideas, and developed a paragraph. They invited the students to share their ideas while they were writing them on the board. After a paragraph had been done, then the students were asked to continue the text individually. As the time was limited, they asked the students to do revision and edition at home. The six other student-teachers, however, made only little improvement. They did guide the students to brainstorm ideas, but they did not model how to write. Then, they asked the students to write individually based on the brainstormed ideas.

\section{b. Instructional Materials}

Instructional materials used by the student-teachers at the second cycle were much better than at the first cycle in terms of their validity, variety, quantity, and quality. At the first cycle the materials were limited on conversation models and monolog text models, and a few written exercises. Materials such as list of vocabulary, examples of the use of expressions in contexts, and some scripts of listening were not included.

Next, some of the materials were not appropriate viewed from the content and the language of the texts. Most of the student-teachers adopted the materials from internet sources. Even though those materials were authentic and appeared to be interesting, it was found that most of the materials were difficult for high school students. This judgment was based on the materials of the textbooks used by high school teachers and the syllabus. The texts were longer and the language was complex. The student-teachers were not aware of this problem because their peers who acted as students did not have difficulties to understand the texts. In addition, one student used 'report' text to teach 'descriptive'.

Because of the problems above, the student-teachers were told to look at the high school textbooks and to compare with the materials they used. They were asked to consider the length of the texts, the language, the validity of the content, and the attractiveness. They were told to write in their journals and to do improvement in the next teaching.

At the second cycle there was improvement. The studentteachers took some materials from the student textbooks, some adopted, and some others were adapted from internet sources. All students included list of important vocabulary and exercises. Two student-teachers included materials for games. Viewed from content and language level, most of the materials were appropriate. In spite of that, a couple of materials adopted and adapted from internet sources contained mistakes/problems. For instance, a text claimed as an exposition text, but it was actually a discussion text. Some adapted sources contained grammar mistakes.

\section{c. Instructional media}

Selecting and using media was the third obvious improvement of the student-teachers' teaching performance. The improvement was seen from the variety of media used, the skill of selecting media, the skill of using media. At the first cycle, all student-teachers used multimedia. None used traditional media such as pictures. All media used were suitable with the topics of the texts taught. However, there were problems in terms of their functions, practicality, and attractiveness. Some media were less functional because they appeared not to help the teachers ease students' understanding, nor to attract students' attention. Some students even seemed to be confused. For example, a student-teacher showed a video of a film thriller which took 3 minutes to watch. There were four teenagers (native speakers) in the film talking about something. Because of the sound and the speed of the talk, most of the students could not catch the content of the conversation. This was seen from the students' expression and reaction when the teacher asked questions about the film. Unfortunately, such quite long film thriller was only intended to introduce an expression of 'congratulation'. Thus, the use of the media was not really functional. Besides that, some girl student-teachers were not really skillful to operate the 
multimedia they had prepared; they needed help from their boy peers.

At the second cycle most of the students still used multimedia, while some used pictures. There was a progress in terms of media selection. As at the first cycle, all media were related to the topics of the lessons. However, some media were not used optimally to help the students understand the lessons. Some student- teachers invested much time for a simple purpose of their media. Pictures were the media that $25 \%$ of the student-teachers used at the second cycle. It was found that some of the media were interesting and helpful as they were big enough in size, colorful, and well drawn. Some, unfortunately, were not interesting, and thus were less functional. The pictures were small and had no colour which made them unseen from the back rows and unattractive.

\section{d. Classroom Language}

Using appropriate and accurate classroom language was another aspect of teaching that became the focus of observation in this study. It was found that this aspect did not have significant progress at the second cycle. The problems were that the student-teachers often used complicated English. They used long sentences which sometimes contained grammar mistakes. For instance, a student-teacher gave an instruction to her students to work in small groups and discussed the text. She said several sentences to give such instruction in English with some grammar and pronunciation mistakes. Their students, her peers, still needed clarification. If such instruction was given too high school students, it would certainly make the students confused. The problem became worse when the student-teachers explained something. To improve this, they were given feedback and examples about using appropriate and accurate classroom language. They were required to watch their video, write in their journals, and practice English much.

At the second cycle a few student-teachers made improvement. They used simple English, which automatically reduced grammar mistakes. Unfortunately, the rest (around $80 \%$ ) did try to use simple sentences, but still contained grammar and vocabulary mistakes. Sometimes their instruction and explanation remained confusing and unclear. In other words, as stated above, the improvement of this aspect was trivial.

In summary, the result of observation affirms previous research showing that reflective (e.g. [22]; [23];[15]; [24]) is useful. It is most likely caused by the fact that reflection provides a room for student-teachers to echo their teaching presentation. As they stated in the interview, they could identify their teaching problems. This is in line with the purposes of reflective teaching pointed by Murphy (2001); that is, to : 1) to expand understanding of teaching-learning process; 2) to expand repertoire of strategic options as a language teacher, and 3) to enhance the quality of learning opportunities. Based on the result of the reflection, they made a plan to improve their next teaching presentation.

\section{Interview}

An interview with the student-teachers was conducted at the end of the second cycle. There were three main questions of the interview, their opinion about reflective teaching, the use of journal, and the use of video-recorded teaching. The result of the interview is explained based on these questions.

\section{a. Reflective teaching}

All of the student-teachers said that reflective teaching was good because this strategy helped them improve their teaching. They stated that through reflection they were aware of their problems in teaching. Some stated that they even understood what they had learned in previous subjects better after they practice teaching and did reflection. A student-teacher, for example, said that she thought that she had to go to 'independent construction' stage of the Genre-Based Approach, even though some students still had problems at 'the joint construction' stage. Another student-teacher mentioned that she could make a better lesson plan because of reflective practice.

In spite of that, it is also interesting to find out that a few student-teachers said that at the beginning of doing reflection, they felt discouraged and shy. They said that they made many mistakes. They also thought that peers' comments were not always right. That's why they asked for more explanation from the lecturer (i.e. the researcher). It was found these student-teachers actually made quite significant improvement at the second teaching presentation.

\section{b. Journal}

The student-teachers agreed that writing journal was beneficial. They stated that by writing what they did in the classroom made them aware of their teaching skills. In addition, as they were required to write what they would improve in the next teaching, they had to think hard before they made their next lesson plans. Even so, a few studentteachers admitted that they could have forgotten some important points because they wrote it two or three days after teaching; they said that they did not have time to write it right after their teaching performance. Some also thought that they were not good at expressing their ideas in the journal. Then, this could have affected their teaching improvement.

\section{c. Video}

Each student-teacher's teaching presentation was video-recorded, and the recording was copied for him/her. The student-teachers were asked to watch the recording and made some notes about their performance.

The result of the interview indicates that the studentteachers felt excited with the recording. They said that they were never recorded, except audio recording for Listening class. They liked watching it even though sometimes they felt shy when they saw their inappropriate body movement/gesture.

All of them agreed that watching video-recording of their own teaching gave several benefits. Firstly, they said that video-recording confirmed lecturer's and peers' comments. 
They found that most of the comments were true. Secondly, they also could see the problems that were not commented by the lecturer and their peers. One of them stated that before watching the video recording she did not know that she stood very awkwardly when she taught. She also found out that she only looked at one side of the class. She said that she improved this at the second teaching presentation. Thirdly, some student-teachers thought that the video recording helped them capture many aspects of the teaching and learning process. They could see their students' reactions. Because of that, as they said, they had better ideas what to improve in the next teaching presentation. When asked whether they felt shy when watching the recording of their own presentation, a few said 'yes', but only a little. Yet, they said 'it is okay' because they watched it by themselves.

Reflective teaching was effective to help the studentteachers improve their teaching skill. This result is in line with previous research findings mentioned in part B Journal appeared to be a good instrument of reflective teaching. In addition to that video recording gave the students-teachers a vivid idea how their teaching was like [8]; [11]. makes the student-teachers able to see their performance. The studentteachers said that by writing what they thought they were not good at yet, what they were good at, and what they had to improve pushed them to make efforts to do better.

\section{CONCLUSION}

This study has affirmed the advantages of reflective teaching on the student-teachers' teaching skill. The results of observation over the two cycles of this study show that the student-teachers' improved their teaching techniques, instructional materials and media, and classroom language use in varying degrees. The result of interview reveals that journal plus video helped the student-teachers them in doing reflection. As explained above, by writing journal they were made aware of the problems of their teaching presentation, and thus planned and prepared better for the following presentation. In spite of that, one the teaching aspects in focus, classroom language, did not show significant progress. As for classroom management, the student-teachers did not have difficulties at the first and the second cycles. Video helped them to see details of their presentation. Based on the findings of this study, it is suggested that reflective teaching using these two instruments are applied in order to help lecturer (s) help student-teachers in Micro Teaching and Teaching Practicum. Other researchers are also suggested to carry out other research about reflective teaching as using different kinds of instruments.

\section{References}

[1] U. Toman, O. S. Cimer, and A. Cimer, "Analysis of pre-service science teachers 'views about the methods which," no. October, pp. 162-172, 2014.
[2] H. D. Brown, Teaching by principles, 2nd ed. New York: Longman, 2001.

[3] N. Uzun, "A sample of microteaching in environmental education and its effect on pre-service teachers' presenting effective lessons," AsiaPacific Forum Sci. Learn. Teach., vol. 13, no. 1, pp. 1-21, 2012.

[4] A. C. Ornstein and F. P. Hunkins, Curriculum: Foundations, Principles and Issues. Boston: Pearson, 2013.

[5] A. Lieberman and D. Wood, "Sustaining the professional development of teachers: Learning in networks," B. Davis, Ed. London: Longman, 2003.

[6] U. Hakan, "Reflective teaching in teaching social skills: Utopia or necessity?," Intercult. Relations Soc., vol. 16, no. 4, pp. 183-188, 2009.

[7] T. J, "Reflective teaching : Exploring our own classroom practice," pp. 2011-2014, 2004.

[8] S. Mohammad Abu Jado Associate Professor Educational Psychology, "The Effect of using Learning Journals on Developing Self- Regulated Learning and Reflective Thinking among Pre-Service Teachers in Jordan," vol. 6, no. 5, pp. 89-104, 2015.

[9] M. Karaca, F. Ö. Armağan, and O. Bektaş, "The use of the reflective diaries in science lessons from the perspectives of eighth grade students," Int. J. Environ. Sci. Educ., vol. 11, no. 2, pp. 53-74, 2016.

[10] S. C. Kong, R. H. Shroff, and H. K. Hung, "A web enabled video system for self reflection by student teachers using a guiding framework," Australas. J. Educ. Technol., vol. 25, no. 4, pp. 544-558, 2009.

[11] H. Fatemipour, "The Efficiency of the Tools Used for Reflective Teaching in ESL Contexts," Procedia - Soc. Behav. Sci., vol. 93, pp. 1398-1403, 2013.

[12] T. C. Ogbuanya, "Effects of Reflective Inquiry Instructional Technique on Students' Academic Achievement and Ability Level in Electronic Work Trade in Technical Colleges," vol. 6, no. 7, pp. 43-54, 2015.

[13] Y. Rozimela and Y. Tiarina, "Raising students' awarenes on their teaching performance through reflective teaching," in Seminar on English Language and Teaching (ISELT), 2014.

[14] J. . Richards and C. Lockhart, Reflective teaching in second language classrooms. Cambridge: Cambridge University Press, 1996.

[15] T. Farrell, "Reflective teaching: the principles and practices," English Teach. Forum, vol. 36, no. 4, pp. 10-17, 1998.

[16] A. Soisangwarn and S. Wongwanich, "Promoting the Reflective Teacher through Peer Coaching to Improve Teaching Skills," Procedia - Soc. Behav. Sci., vol. 116, pp. 2504-2511, 2014.

[17] R. M. Arnold, W. Baile, J. A. Tulsky, F. Petracca, and A. Back, "Reflective teaching practices: an approach to teaching communication skills in a small-group setting.," Acad. Med., vol. 81, no. 7, pp. 638644, 2006.

[18] K. M. Bailey, Language teacher supervision. Cambridge: Cambridge University Press, 2006.

[19] R. Serra, "What Is Reflective Teaching And Why Is It Important," 2015. [Online]. Available: http://wwwrichmondshare.com.br/what-isreflective-teaching-and-why-is-it-important. [Accessed: 15-Dec-2016].

[20] Y. Yang, "Teaching Chinese college ESL writing: A Genre-based Approach," English Lang. Teach., vol. 9, no. 9, p. 36, 2016.

[21] Y. Sawangsamutchai and S. Rattanavich, "A Comparison of Seventh Grade Thai Students' Reading Comprehension and Motivation to Read English through Applied Instruction Based on the Genre-Based Approach and the Teacher's Manual," English Lang. Teach., vol. 9, no. 4, p. $54,2016$.

[22] I. . Cornford, "Reflective teaching: Empirical research findings and some implications for teacher education," J. Vocat. Educ. Train., vol. 54, no. 2, pp. 219-235, 2002.

[23] A. . Cirocki, S. Tennekoon, and A. . Calvo, "Research and reflective practice in the ESL classroom: Voices from Sri Lanka.," Aust. J. Teach. Educ., vol. 39, no. 4, pp. 24-44, 2014.

[24] Y. Rozimela, 'Understanding prospective teachers' concerns in EFL teaching through reflective practice," Int. J. Sci. Res., vol. 4, no. 4, pp. 68-74, 2015. 